\title{
ANALYSIS OF THE INTERNATIONAL EXPERIENCE OF IMPLEMENTING BLOCKCHAIN TECHNOLOGY
}

\author{
Dilmurod Azimov
}

\author{
Tashkent State University of Economics, Tashkent, Uzbekistan \\ e-mail:d.azimov@tsue.uz
}

Received: 20 January 2021; Accepted: 20 April 2021 Published: 01 May 2021

\begin{abstract}
Background: Today, blockchain technology is of interest in both the technology and business sectors. The information technology industry is developing very rapidly in our time, and new technologies appear so often that specialists often do not have time to react to their appearance. One of the striking examples of modern information technology potentially capable of changing the organization of effective economic management is the technology of distributed ledgers. Blockchain technology is "cross-cutting", that is, one that can be applied in many areas of the economy, management, including state, municipal and social spheres. This paper determines by the provisions and the need to form the basis for the prospective assessment of the consequences of the implementation of blockchain technology, both nationally and internationally and collect information on the state of the issue, comparison of information for a transaction using blockchain technology in the supply chain of logistics, proposing the model implementation and future research and recommendations.

Methods: review of literature on the introduction of blockchain technology allows us to determine the current state of research issue, to note the lack of knowledge of blockchain technology and the use of a wide range of consumers. In this regard, it is necessary to conduct an analysis of the implementation of blockchain technology from the world experience.

Results: the orientation of the introduction of blockchain technology to the technological side of logistics reduces risks and significantly increases stability since it forms its practical orientation. The introduction of blockchain technology in the industry is beneficial for increasing the efficiency of the workflow, data storage, managing the supply of goods, reducing errors in the document flow and its duration, reducing the duration of the logistics cycle.

Conclusions: after reviewing the international experience in implementing the blockchain, it was concluded that entrepreneurs and authorities should constantly find new ways of methodological aspects of blockchain research and mechanism of applying technologies in the modern economic system. This experience shows that using blockchain technology in combination with other technologies can significantly reduce paperwork and growth of business activity, as well as reduce costs and increase efficiency. Also, based on the analysis results, we can formulate a conclusion that logistics is an industry in which the use of blockchain technology can solve the security problem in this area, as well as simplify and reduce the cost of transporting goods through smart contracts.
\end{abstract}

Keywords: Blockchain technology, supply chain management, logistics, transport logistics, information, supply tracking

JEL classification: M21, C89, C50, C60

Citation:

Azimov, D. (2021). Analysis of the international experience of implementing blockchain technology. Access to science, business, innovation in digital economy, ACCESS Press, 2(2): 138-149. https://doi.org/10.46656/access.2021.2.2(2)

\section{INTRODUCTION}

Today, many developed countries pay great attention to the development of the digital economy, in particular the blockchain technology, there by adopting new legislative acts and state programs, gradually introducing digitalization in all areas of the economy and creating infrastructure for the 
development of the digital economy. The states take large-scale measures to develop the digital sector of the economy. Electronic document management systems are being introduced, electronic payments are being developed, and the regulatory framework in the field of e-Commerce is being improved. Digital economy platform is evolving on information technology platforms and is developing at an intensive rate, which makes it necessary to create new models of such platforms.

"Blockchain" technologies (distributed data registry technologies)," artificial intelligence", the use of the capabilities of supercomputers, as well as activities on crypto assets are one of the directions of development of the digital economy in many countries of the world. Blockchain technologies are gradually being implemented not only in many sectors of the economy, but also in the public administration system and other public relations ${ }^{1}$.

In modern transport logistics, when choosing optimal routes and transport, computer processing of raw data (orders, cargo parameters, vehicle fleet, etc.) is necessary. This is due to the constantly growing volumes of data on the state of management facilities. (Here in after referred to as the OU). Data about the shelter is sent to the control center in a "closed" form from satellites, and the manual processing of such a flow of information becomes time-consuming, which leads to a loss of efficiency of decisions made and an increase in the number of errors.

There are also studies of the features of the use of blockchain technology in the financial and banking sectors (Korchagin, 2016; Trufanov, 2017). The relevance of the analysis of the experience of implementing blockchain technology is determined by the above provisions and consists in the need to form a basis for a long-term assessment of the consequences of implementing this technology both at the national and international level.

\section{Literature Review}

A possible solution to this problem in logistics systems may be the introduction of blockchain technology. A blockchain (English: Block chain or chain of blocks) is a continuous sequential chain of blocks (linked list) that contains information in accordance with certain rules. Most often, blockchain provides a decentralized and self-regulating data infrastructure in which all data and transactions are stored ( $\mathrm{Li}, 2019)$. Due to the fact that all blocks in this technology are interconnected and in most cases are not subject to change, this technology can solve the security

\footnotetext{
${ }^{1}$ Resolution of the President of the Republic of Uzbekistan Sh. M. Mirziyoyev dated July 3, 2018 No. PP-3832 "on measures for the development of the digital economy in the Republic of Uzbekistan". https://lex.uz/ru/docs/3806048
} 
problem in logistics, namely, prevent the possibility of data modification and falsification by hackers.

Blockchain technology is a distributed resource technology, and its development has been recognized as a priority by the Uzbek government. There are also studies of the specifics of using blockchain technology in the financial and banking sectors (Osmani et al., 2020). Information security, including in the financial sector, has received considerable attention from researchers and scientists (Osmani et al., 2020). The user can point out specific problems, such as the technical problem of verifying a block of data, which is performed discretely, the problem of a small number of specialists in the use of this technology, and the lack of clear rules and norms for the transaction rule using blockchain technology.

The relevance of the analysis of the experience of implementing blockchain technology is determined by the following provisions and consists in the need to form a basis for a prospective assessment of the consequences of implementing this technology, both at the national and international level.

Tracking refers to the backward tracking of products, and tracking refers to the direct monitoring of the products. Few researchers have also mentioned that product traceability is mainly related to quality and safety assurance, but rarely related to business development and logistics improvement (Behnke \& Janssen, 2020). However, the ability to combine high-quality product information with logistics information is constantly missing from the existing product supply chain infrastructure. By using sensors and IoT devices installed at every checkpoint (product value added) throughout the supply chain, this problem can be solved by constantly tracking both the quality information and the physical movement of the product. In the blockchain network, each product becomes an asset, and each IoT update serves as transactions performed with the asset. So, with a unique product identifier, any type of product can be tracked and tracked for quality assurance and logistics activities.

The reference literature provides data on the potential benefits of using technology to improve product identification, food safety and quality measurement, packaging, and software development. Another important reason for implementing technology is to attract customers and simplify their purchases.

Currently, 21 and a growing number of companies are using blockchain for asset management, identity management, and authentication of important documents such as passports, birth certificates, and Internet account logins, creating a digital identifier that combines decentralized 
blockchains with identity management (Kuperberg, 2020). However, very few companies, such as Provenance, Block verify, QuickBooks, Everledger are focused on improving product provenance in a wide range of products such as fish, luxury items such as diamonds, expensive handbags and tracking the origin of pharmaceuticals.

IT-enabled product tracking system was also proposed which uses all the logistics information to improve supply planning and overall logistics operations. The current architecture, which was mainly used in modern product chains, as shown in figure 3-2, uses a centralized database that collects information about product characteristics only when it reaches the distributor and then the retailer. This is primarily applicable in a centralized retail supply chain, where retailers own their distribution network and logistics.

Information about the product at the initial stages from the processor to the farm is stored in the form of database repositories in the form of Excel sheets and printed copies. Optimizing data collection, data exchange, and data security is a prerequisite for creating an end-to-end tracking system, which can be either a conventional it system or a blockchain.

\section{Methodology}

The review of literature on the introduction of blockchain technology allows us to determine the current state of research, to note the lack of knowledge of blockchain technology and the use of a wide range of consumers. In this regard, it is necessary to conduct an analysis of the implementation of blockchain technology from the world experience. Areas of application of blockchain technology in the modern economic system are constantly expanding. Major multinational corporations give priority to digital technologies and make capital investments in related developments, including the creation of a blockchain system and its implementation in the construction of the supply chain. To these companies include a manufacturer and supplier of hardware and software, "IBM", retail chain "Walmart" leader Online trading companies "Amazon", multinational manufacturing companies "Unilever" and "Nestlé", the freight forwarding company "UPS", etc.

Based on the review of articles of scientific publications published abroad, it is possible to determine the main directions of research in the field of blockchain:

- theoretical and methodological aspects of blockchain research; definition of the essence and mechanism of construction;

- advantages and risks of using blockchain, impact on the growth of business activity of business entities; 
- blockchain as the basis for the development of smart contracts in business ${ }^{1}$;

- legal regulation of relations arising from the use of blockchain technology and cryptocurrency related to circulation (the issue of legal regulation of relations using the distributed registry system in logistics and supply chain management was not considered);

- the use of blockchain technology in the public and commercial sphere, including in certain industries and spheres of activity.

\section{Analysis and Results}

Initially, the blockchain among entrepreneurs was associated only with the financial sector, in particular with the circulation of cryptocurrencies. Currently, there is a steady growth in the number of branches of technology being studied.

The blockchain allows you to track all the movements of goods and fix all links in the supply chain, as well as provide irrefutable evidence about the country of origin and logistics processing of goods.

Figure 1 shows the degree of influence of blockchain technology on individual functional areas of the organization ${ }^{2}$.

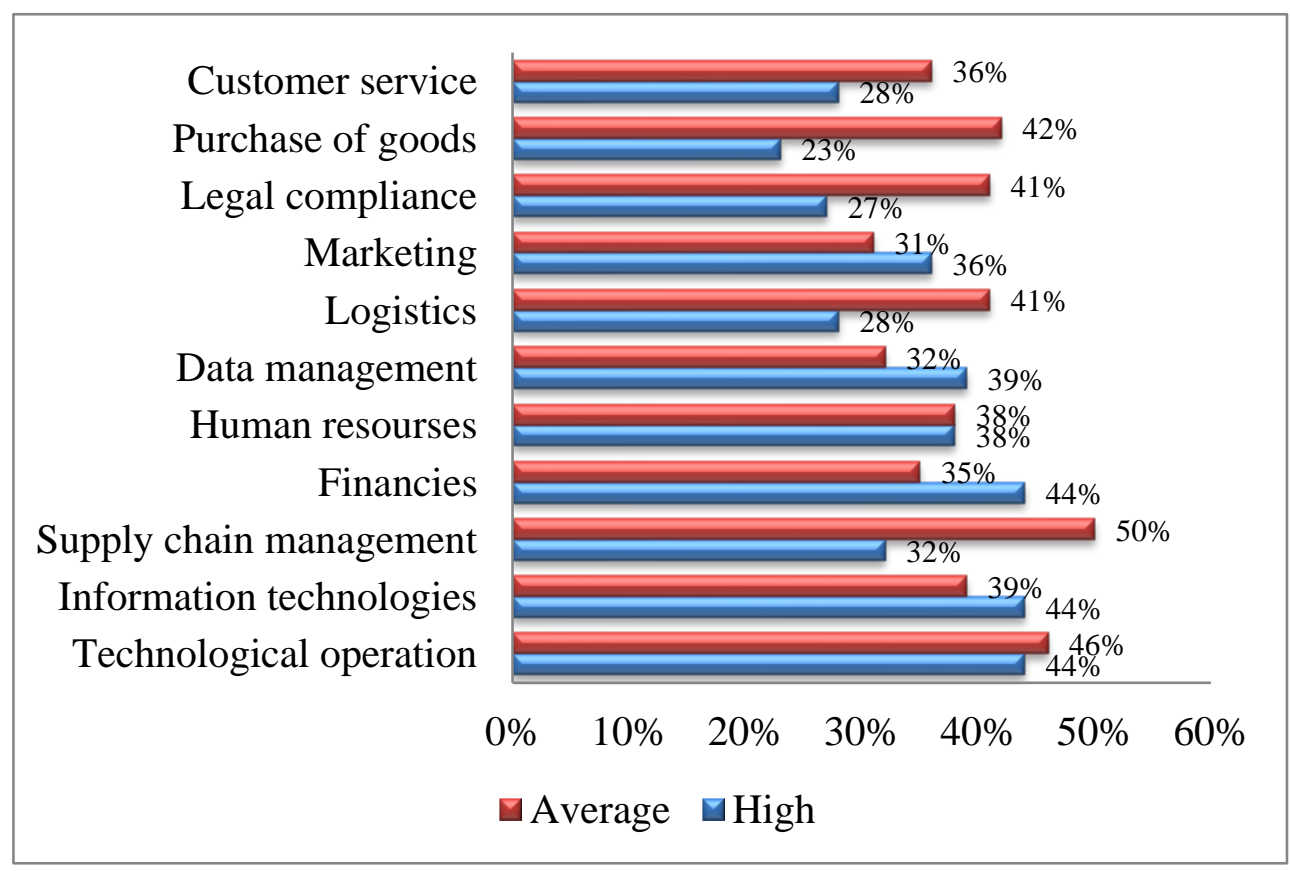

Fig. 1. Assessment of the surveyed foreign companies that have implemented blockchain technology, $\%$

Source: Created by author

\footnotetext{
${ }^{1}$ Retail: Opening the Doors to Blockchain. URL: https://www.cognizant.com/whitepapers/retail-opening-the-doors-toblockchain-codex2879.pdf.

${ }^{2}$ Chainstep. Blockchain in use. URL: https://www.chainstep.com/ use- cases/?lang=en.
} 
Walmart, the world's leading retailer, was one of the first to use blockchain technology in trade. In 2016, it launched a pilot project to use blockchain technology in the supply of pork from China. In addition to Walmart itself, Tsinghua University in Beijing and IBM Corporation participated in the implementation of the project in order to improve the tracking system for goods transported from China.

The next example of using blockchain technology by a walmart trading company is the delivery of mangoes from Mexico. In 2018, the international retail chain Carrefour, based in France, announced the expansion of the use of blockchain technology. Buyers are offered the opportunity to track the entire chain of movement of livestock products and vegetables. After reading the QR code placed on the goods, the consumer can find out all the details of the origin of goods, their transportation and storage using a smartphone. Having analyzed the practice of using blockchain in various areas of activity based on the data presented on the CHAINSTEP website (Nir Kshetri, 2018), we can conclude that it is supply chain management and logistics that are the areas of activity in which the blockchain has the greatest potential for development. Thus, as of March 10, 2018, out of 453 cases of implementation of blockchain technology, 61 projects accounted for supply chain management, transport, logistics (while the largest number of projects still belongs to the Finance sector -116) (Korchagin, S. (Ed.) 2016).

Currently, a blockchain trading platform for the global logistics industry, developed by IBM in collaboration with the world leader in container shipping, the Danish company Maersk, is being developed and tested to create a digital trading platform based on open standards, designed to exploit the global logistics ecosystem.

As follows from table 1, blockchain technology in the field of logistics can be used both in individual domestic markets and internationally. Blockchain in supply chain management is more often used in the following main functional areas: documenting logistics operations, concluding contracts and ensuring compliance with other multilateral agreements, tracking cargo, financial support for the logistics process, and so on.in 2017 - early 2018, pilot projects were launched to use blockchain technology in the field of nutrition of such food groups as fruits and vegetables, animal products, fish and seafood.

Table 1. Examples of blockchain applications in supply chain management

\begin{tabular}{|l|l|}
\hline THE PROJECT & BRIEF CHARACTERISTICS OF \\
\hline "EverLadger" https://www.everledger.io & Tracking the origin of diamonds. The company was \\
\hline
\end{tabular}




\begin{tabular}{|c|c|}
\hline & $\begin{array}{l}\text { founded in April } 2015 . \\
\text { L. Kemp (Kemp Leanne) }\end{array}$ \\
\hline $\begin{array}{l}\text { Service Ripe.io - tracking deliveries of agricultural } \\
\text { products ("from bed to plate») http://www.ripe.io }\end{array}$ & $\begin{array}{l}\text { The system registers the ripeness, humidity and } \\
\text { temperature of products. The farmer can monitor what } \\
\text { happens to his product on the way, adjust the } \\
\text { collection and delivery system based on the data } \\
\text { obtained, and most importantly - always know in what } \\
\text { condition his customer received the products. }\end{array}$ \\
\hline $\begin{array}{l}\text { Provenance - tracking food supplies to stores and } \\
\text { restaurants } \\
\text { http://www.provenance.org }\end{array}$ & $\begin{array}{l}\text { Currently, more than } 200 \text { retailers and manufacturers } \\
\text { in the food and beverage industry in the UK use the } \\
\text { "Provenance" software. } \\
\text { Users have the ability to track the movement of food } \\
\text { items from the moment of production to hit the } \\
\text { shelves. } \\
\text { You can not only check the quality of the product, but } \\
\text { also find out whether it is legally produced. }\end{array}$ \\
\hline $\begin{array}{l}\text { IMMLA - international multi modallogistics } \\
\text { application http://immla.io }\end{array}$ & $\begin{array}{l}\text { a Logistics solution that combines instant processing } \\
\text { of applications and conclusion of contracts for multi- } \\
\text { modal transportation based on the best price principle. } \\
\text { It provides interaction between the cargo owner and } \\
\text { the carrier at all stages of the cargo transportation } \\
\text { process based on the Etherium blockchain and smart } \\
\text { contracts. } \\
\text { The founders are "SB Solutions "(an IT company with } \\
\text { a focus on logistics), as well as the leaders of the } \\
\text { logistics industry "Global Transport Investments" and } \\
\text { "Hellmann Worldwide Logistics". }\end{array}$ \\
\hline
\end{tabular}

Source: Created by author (Korchagin, S. (Ed.) 2016)

\section{Proposed Implementation Model}

Implementation work should be carried out in accordance with the guidelines, regulatory and methodological documents. The purpose of the implementation is to develop software for the formation of a single information field based on blockchain technology. We recommend highlighting the following stages of blockchain implementation in a modern industrial enterprise:

- assessment of the possibility of introducing blockchain into an enterprise. At this stage, the following information about the enterprise is required - the number of employees, turnover, industry, length of the production cycle, the number of customers, availability of warranty periods and service conditions (Abdullayev, Saidahror \& Ayupov, 2020). Based on this data, programmers process the received data and calculate the timing implementation of blockchain technologies in the company, its cost, economic efficiency and risks. Based on the received blockchain analysis, the enterprise decides on the need to implement the technology;

- development of a blockchain system for an enterprise. At this stage, the enterprise has two options. First, blockchain algorithms are currently developed for each industry and enterprise size 
that can be used for adaptation at the level of a particular organization. The availability of a readymade core of the program allows you to reduce implementation costs by up to $70 \%$ and speed up the process of implementing blockchain technologies. The second is the adaptation of the algorithm to the order of the enterprise. In this case, the enterprise provides all the information about the required blockchain platform administration system, which further adapts the existing templates for the individual enterprise. The choice of the required option is carried out by the management of the enterprise based on the interests of the management, the specifics of the work and the level of confidentiality of information;

- implementation of a blockchain system in an industrial enterprise. At this stage, the system is launched and its effectiveness is assessed. It is being finalized within the framework of the identified shortcomings or improvement opportunities;

- monitoring the implementation of blockchain technology. An enterprise implementing distributed ledger technology can generate a monthly report on the progress of the blockchain system implementation. Based on this report, the system formulates recommendations for improving the blockchain system and their economic justification;
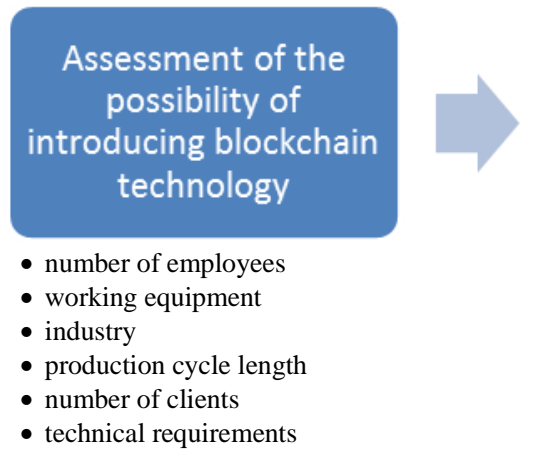

Implementation of

blockchain technology

in the enterprise

- system start

- efficiency mark

type

- platform choice

- algorithm creation

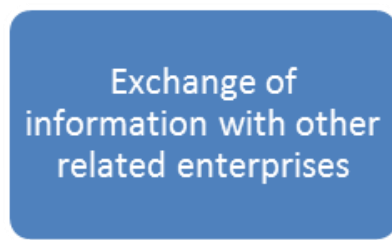

- integration of best practices

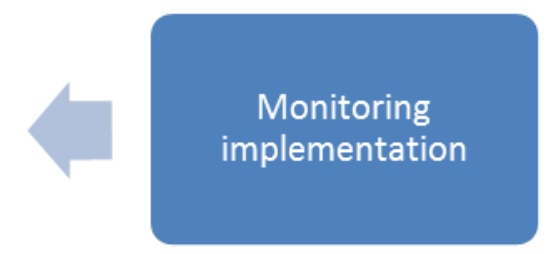

- report generation - recommendations for improvement

Fig. 2. A model for the implementation of blockchain technology in an industrial enterprise Source: Created by author

- participation of an enterprise in the blockchain community through the generalization of implementation results and exchange of information with partner companies within their industry or 
related fields of activity. Exchange of information allows you to popularize the company as a technology leader and attract new customers, partners or investors. The information collection function allows you to integrate best practices in the blockchain field and make the enterprise one of the leaders in the field of distributed ledger technologies. Figure 9 shows a model for implementing blockchain technology in an industrial enterprise.

This implementation approach allows at the early stages of implementation to assess the prospects of blockchain for an enterprise, or to diversify risks by implementing blockchain as part of a separate business process.

\section{Future Research and Recommendations}

Blockchain technology positively affects the solution of key problems of supply chain management, including the reliability, stability and flexibility of the supply chain (Paliwal et al., 2020).

The following advantages of using blockchain in supply chain management are proposed:

- reducing logistics costs across the entire supply chain;

- reducing systemic risks in operational activities (Nigmatulin, Krasnova, Lavrinovich, 2016., p. 31);

- improving product safety, reducing losses in the process of delivery and storage of goods;

- ensuring transparency and reliability of information about manufacturers (suppliers) of goods and the process of their distribution;

- ensuring complete anonymity of all transactions in case of implementation of closed solutions (Trufanov, 2017, p. 50);

- achieving a high degree of flexibility in the supply chain;

- providing unlimited storage of permits and accompanying digital documents, including certificates, licenses, confirmation of excise payments, etc. (Nigmatulin, Krasnova, Lavrinovich, 2016, p. 13);

- increase the speed of customs clearance of goods in international trade;

- ensure closer relationships and coordination between all supply chain participants;

- ensuring consumer rights by providing complete and irrefutable information about the origin of goods obtained in a retail chain;

- increasing opportunities for fair trade and green logistics development;

- reducing the number of diseases associated with the use of low-quality, contaminated food; 
- applying a dynamic pricing strategy in the service sector that can be built on the basis of real data, for example, taking into account actual delivery speeds, climatic conditions, and so on.

Based on the review of the state of the issue, literature, and comparison, it is possible to determine the main directions for future research in the field of blockchain:

- theoretical and methodological aspects of blockchain research, definition of the essence and mechanism of construction;

- advantages and risks of using blockchain, impact on the growth of business activity of business entities;

- blockchain as the basis for the development of smart contracts in business (Strembitskaya, Babayan, 2017, pp. 136-147);

- legal regulation of relations arising from the use of blockchain technology and cryptocurrency related to circulation (the issue of legal regulation of relations using the distributed registry system in logistics and supply chain management was not considered);

- the use of blockchain technology in the public and commercial sphere, including in certain industries and spheres of activity.

\section{CONCLUSION}

Blockchain in supply chain management is a technology that allows transactions between peer-topeer networks while managing material, information, financial, and service flows. Over the past two years, key blockchain technology projects have been implemented in the field of food supplies (vegetables and fruits, animal products, fish, and seafood).

After reviewing the international experience in implementing the blockchain, it was concluded that entrepreneurs and authorities should constantly find new ways of methodological aspects of blockchain research and mechanism of applying technologies in the modern economic system. This experience shows that using blockchain technology in combination with other technologies can significantly reduce paperwork and growth of business activity, as well as reduce costs and increase efficiency. Also, based on the analysis results, we can formulate a conclusion that logistics is an industry in which the use of blockchain technology can solve the security problem in this area, as well as simplify and reduce the cost of transporting goods through smart contracts. The orientation of the implementation of blockchain technology to the technological side of logistics reduces risks and significantly increases stability, since it forms its practical orientation. The introduction of blockchain technology in the industry is beneficial for improving the efficiency of the workflow, 
storing data, managing the supply of goods, reducing errors in document flow and its duration, reducing the duration of the logistics cycle.

Summing up in the near future, the scope of effective research of blockchain technology in supply chain management will be expanded. Blockchain technology will cover both the supply of food and non-food products; first of all, it concerns goods for which there is a high proportion of counterfeit and substandard products.

\section{Conflict of interests}

The authors declare no conflict of interest.

\section{References}

Abdullayev, M., Saidahror, G., \& Ayupov, R. (2020). Raqamli iqtisodiyot - kadlar tayorlashning dolzarb yo'nalishlari. Archive of Scientific Research, 1 (23). Retrieved from https://journal.tsue.uz/index.php/archive/article/view/2702.

Behnke, K., \& Janssen, M. F. W. H. A. (2020). Boundary conditions for traceability in food supply chains using blockchain technology. International Journal of Information Management, 52. https://doi.org/10.1016/j.ijinfomgt.2019.05.025

Chainstep. Blockchain in use. URL: https://www.chainstep.com/ use- cases/?lang=en.

Doszhan, R., Nurmaganbetova, A., Pukala, R., Yessenova, G., Omar, S., \& Sabidullina, A. (2020). New challenges in the financial management under the influence of financial technology. In E3S Web of Conferences (Vol. 159, p. 04015). EDP Sciences.

Korchagin S. (2016). On current trends in the development of blockchain technology // Free Thought. 2016. Vol 4 (1658). p. 31-38.

Kshetri, N. (2018). 1 Blockchain's roles in meeting key supply chain management objectives. International Journal of Information Management. Information Management, 2018, Vol. 39, pp. 80- 89. https://doi.org/10.1016/j.ijinfomgt.2017.12.005

Kuperberg, M. (2020). Blockchain-Based Identity Management: A Survey from the Enterprise and Ecosystem Perspective. IEEE Transactions on Engineering Management, 67(4). https://doi.org/10.1109/TEM.2019.2926471

Li, Y. (2019). Emerging blockchain-based applications and techniques. In Service Oriented Computing and Applications, Vol. 13, Issue 4. https://doi.org/10.1007/s11761-019-00281-x

Nigmatulin T.A., Krasnova A.I., Lavrinovich A.A. (2016). Prospects for the use of blockchain technology by the customs authorities of the Russian Federation // Uchenye zapiski Sankt-Petersburg im. V.B. Bobkov Branch of the Russian Customs Academy. 2016. Vol 4 (60). p. 11-14.

Osmani, M., El-Haddadeh, R., Hindi, N., Janssen, M., \& Weerakkody, V. (2020). Blockchain for next generation services in banking and finance: cost, benefit, risk and opportunity analysis. In Journal of Enterprise Information Management. https://doi.org/10.1108/JEIM-02-2020-0044

Paliwal, V., Chandra, S., \& Sharma, S. (2020). Blockchain technology for sustainable supply chain management: A systematic literature review and a classification framework. In Sustainability (Switzerland), Vol. 12, Issue 18. https://doi.org/10.3390/su12187638

Ramazanov, S., Stemplewska, L. (2020). Decision-making in conditions of dilemma: risks and mixed information uncertainty. Access to science, business, innovation in digital economy, ACCESS Press, 1(2): 112-121, https://doi.org/10.46656/access.2020.1.2(3)

Retail: Opening the Doors to Blockchain. URL: https://www.cognizant.com/whitepapers/retail-opening-the-doors-toblockchain-codex2879.pdf

Resolution of the President of the Republic of Uzbekistan Sh. M. Mirziyoyev dated July 3, 2018 No. PP-3832 "On measures for the development of the digital economy in the Republic of Uzbekistan". https://lex.uz/ru/docs/3806048 
Strembitskaya, S. B., Babayan, S.G. (2017). Cryptocurrency in the Financial Services Sector: New Opportunities on the Example of Blockchain, European Scientific Conference: Sat. Art. International scientific and practical conference under the general. ed. G.Yu. Guliaeva, pp. 146-148.

Trufanov S.A. (2017). The future of management, marketing and production in the context of the development of information technology and the evolution of generations // Economics. Control. Finance. Vol 3 (9). p. 45-56.

\section{About the author}

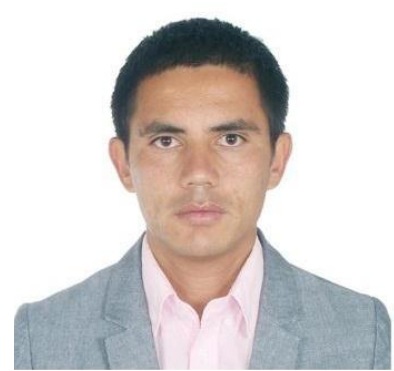

\section{Dilmurod AZIMOV}

Tashkent State University of Economics, Faculty of Digital Economy, Department of Digital Economy and Information Technologies. Scientific interests: Electronic Market Design, Knowledge and Innovation Management, Business IT; Electronic Commerce, Algorithmic Knowledge Management Theory

ORCID ID: https://orcid.org/ 0000-0001-7024-6792

Copyright (C) 2020 by author(s) and ACCESS Publishing Press This work is licensed under the Creative Commons Attribution International License (CC BY) 